\title{
Vaginal bleeding patterns among users of a single implant contraceptive containing 3-ketodesogestrel (Implanon $\left.{ }^{\circledR}\right)$
}

Biran Affandi

\begin{abstract}
Abstrak
Untuk menilai pola perdarahan pada pemakai Implanon ${ }^{\circledR}$ dilakukan analisis "diary card" pada 200 wanita pemakai Implanon ${ }^{\mathbb{}}$. Analisis dibuat berdasarkan "reference period (RP)" yang dikembangkan oleh World Health Organization. Pola yang didapatkan adalah sebagai berikut: jumlah hari perdarahan bercak paling tinggi pada RPI $(26,7$ hari). Selanjutnya makin menurun. Jumlah episode perdarahan-bercak relatif tetap $\left(2,9\right.$ episode). Pada dua tahun pertama, terjadi amenorea pada 7,6 - 12,4\% pemakai Implanon ${ }^{\circledR}$. Kemudian secara berangsur-angsur menurun pada tahun ke-3 dan ke-4. Perdarahan yang tidak teratur dan lama berangsur-angsur menghilang.
\end{abstract}

\section{Abstract}

This is the second paper of three papers reported the results of Phase II Study with single implant contraceptive releasing 3-ketodesogestrel (Implant). This paper reports the analysis of the menstrual diary records of 200 women who participated in the above-mentioned study. The analysis was based on WHO reference period. The patterns show the highest of the mean member of bleeding-spotting days (26.7 days) during the first reference period which then decrease with time. The bleeding-spotting episodes are relatively constant (2.9 episodes) through the study. Ammenorrhoea was experienced by $7.6-12.4 \%$ of the subjects during the first two-year. A gradual decrease occurred in year-3 and year-4. Incidence of infrequent, frequent, and prolonged bleeding were diminished with time.

Keywords: Implanon ${ }^{\oplus}$, implant contraceptive, bleeding patterns

Available data indicates that the most important problem with presently available contraceptive methods is that people simply are not using them. From the family planning program point of view the reasons for the people not using contraceptive methods may be divided into two main categories; the problem of availability and the problem of performance. There can be no doubt that a wide range of contraceptive methods made available can only help to increase contraceptive use and continuation rates. Experience in family planning programs has shown that every new contraceptive method attracts a new group of acceptors who would probably not otherwise have used a contraceptive method at all. 8 The above facts strongly suggest that there is indeed a major need for the development of a variety of contraceptive methods to suit the different requirements of the different stratas of society. 1

Progestin-only contraceptive methods were developed in order to avoid certain side effects and risks

Klinik Raden Saleh, Department of Obstetrics and Gynecology Faculty of Medicine, University of Indonesial Dr. Cipto Mangunkusumo National Hospital, Jakarta, Indonesia associated with the estrogens in combined oral contraceptives. However, minipils, a progestin-only oral contraceptive, have a limited contraceptive efficacy that depends very much on the woman's compliance with the pill regimen. In order to increase contraceptive efficacy without considerable dose increases, non-oral systems that gradually release the progestin have been developed which include, among others, vaginal rings, injectables and subdermal implants.

The main side-effects of progestin-only contraceptive methods are disruption of vaginal bleeding patterns which in turn lead to discontinue the method use.2-8

NV Organon (Oss, The Nederlands) has developed a single-rod implant (Implanon ${ }^{\circledR}$ ) with a length of 40 $\mathrm{mm}$ and a diameter of $2 \mathrm{~mm}$, which is applied subdermally by a disposable sterile inserted. The rod is made of an ethylene vinyl acetate copolymer (EVA) with a core containing approximately $68 \mathrm{mg}$ of $3-\mathrm{ke}-$ todesogestrel or etonogestrel (ENG).

The initial release rate of the implants is approximately $67 \mu \mathrm{g} / \mathrm{day}$ which slowly decreases over time. The constant release profile results in sufficiently high plasma ENG concentrations ( $>90 \mathrm{pg} / \mathrm{ml}$ ) to inhibit ovulation for at least three years.5,6 
ENG is a progestin, structurally derived from 19nortesterone, it is the biologically active metabolite of desogestrel (DSG). DSG is the progestin component of a number of widely used oral contraceptives with a well established efficacy and safety profile. The characteristics of the implant's EVA membrane, combined with the high specific progestin activity of ENG, allow the use of a single-rod system with a low and almost zero order release. As a consequence of these properties, dose-related side-effects are minimized.

About $25 \%$ of progestin-only pill users discontinued the method use due to menstrual disturbances. At the end of the first year of DMPA use, the incidence of amenorrhea is $40 \%$, while $30 \%$ of the users experience irregular or prolonged bleeding. ${ }^{9}$ Menstrual patterns among Norplant ${ }^{\circledR}$ users are irregular and prolonged (spotting) which are diminished with time.5

This paper is the second paper of Phase II Study with Implanon ${ }^{\circledR}$. The Objective of this paper is to report the bleeding patterns among the Implanon ${ }^{\circledR}$ users based on the diary-card collected during the study.

\section{MATERIALS AND METHODS}

\section{Characteristics of subjects}

The inclusion criteria were age between 18 and 40 years, sexually active and of childbearing potential, good physical and mental health, normal cycles with a length of $24-35$ days and a variation of $\leq 3$ days, ability and willingness to accurately fill in the diary card with information on bleeding, accept the implant as the sole method of contraception, willing to return to the clinic at the stipulated time-points, and willing to give informed written consent.

The exclusion criteria were: pregnancy, breast feeding, within two weeks after an abortion, before the first menses after delivery, use of an injectable or implant hormonal method of contraception within a period of six months or the use of other hormonal contraceptives within a period of two months, history of ectopic pregnancy, past of present significant gynecological disorders of the uterus and/or the ovaries, uncontrolled significant endocrine disorder, haemoglobin $(\mathrm{Hb})$ less than $10 \mathrm{~g} / \mathrm{dl}$, breast discharge (other than lactation), past or present disturbance of liver function i.e. cholestatic jaundice, a history of jaundice of pregnancy or jaundice due to previous (oral) contraceptive use, Rotor syndrome or Dubin Johnson syndrome, history of hyperlipoproteinaemia, hypertension i.e. systolic BP > $140 \mathrm{~mm} \mathrm{Hg}$ and/or diastolic $\mathrm{BP}>90 \mathrm{mmHg}$, use of one or more of the following drugs: sex steroids, hydantoins, barbiturates, primidone, carbamazepine, rifampicin and griseofulvin, a history of (within 12 months) alcohol or drug abuse, and administration of investigational drugs within 3 months prior to this study. Two hundred women were recruited in the study.

\section{Characteristics of implant}

Implanon ${ }^{\circledR}$ is a single-rod implant with a length of 40 $\mathrm{mm}$ and a diameter of $2 \mathrm{~mm}$ containing approximately $68 \mathrm{mg}$ of ENG. The rod is made of EVA membrane. The initial release rate of ENG from Implanon (i) is approximately $67 \mu \mathrm{g} /$ day.

Implanon ${ }^{\circledR}$ was delivered in the needle of a sterile, disposable, specially designed inserter individually packed in an aluminium sachet. The sachets were labelled with the protocol number, storage conditions, information on content of sachet, expiry date, packing number and the subject number.

In normal cycling women insertion of the implant was to be performed between the first and the fifth day of the subject's menstrual flow. Implanon ${ }^{\circledR}$ was inserted on the inside of the upper (non-dominant) arm 6 to $8 \mathrm{~cm}$ above the elbow in the groove between the biceps and triceps (sulcus bicipitalis medialis). The area of insertion was throughly cleansed with an antiseptic prior to insertion.

The inserter was entered through the subdermal layer to the full length of the needle. The seal of the inserter was broken by pressing the plunger support. The plunger was turned 90 or 180 degrees. While the plunger was fixed againts the arm, the inserter was slowly pulled out of the arm. A pressure bandage with sterile gauze was applied to minimise bruising. The subjects was to keep the bandage clean and dry during days.

Before removals the implant was located by palpation. The subject's arm was washed and antiseptic applied. A small amount of local anaesthetic (1\% lidocaine) was applied under the implant. After making a $2 \mathrm{~mm}$ incision, the implant was gently pushed toward the incision until the tip was visible. The implant was the grasped with forceps and removed. If the implant could not be pushed into the incision, closed forceps were inserted into the incision in order to gently dissect the tissues around the implant. While the tissues 
were being dissected, the implant was pushed toward the incision. After removal of the implant, the incision was closed and bandaged.

\section{Design of study}

If a subject met all entry criteria and a written informed consent from was signed, screening assessment were to be done. Results of these assessment had to be available before implantation.

The experimental flow of the study after completion of the screening assessment is demonstrated in Table 1. The implant was to remain in situ for 24,36 or 48 months, depending on the willingness of the volunteers to give their consent to the extension of the study. Assessments were scheduled at 3-month intervals during the study. To allow some flexibility to the subjects, a 1-month deviation was allowed. During the whole study period occurrence of adverse experiences as well as use of concomitant medication were reported. If suspected at any time in the study, a pregnancy test was performed. Data on the subjects' bleeding pattern were recorded by the subject on a daily basis in a diary card.

\section{Reference period analysis}

The analysis of the bleeding pattern, as recorded by the subjects on the diary cards, was performed by a reference period analysis as described in the WHO Special Programme of Research Training in Human Reproduction by Belsey et al,10 Belsey and Farley.11

The reference period analysis defines the subject as the unit of analysis. All subjects' diaries were divided into consecutive periods (so-called reference periods), starting with the day of implant insertion as first day of the first reference period (Day 1). One additional reference period (denoted as period \#) was defined which starts 28 days after implant insertion. Within each reference period, medically relevant bleeding-spotting (BS) variables are summarised. This analysis was based on the following subject response categories per day: bleeding, spotting, bleeding-free, and missing response.

The reference period analysis included all subjects treated (with some data excluded) who had at least one evaluable reference period, based on the following guidelines:

\section{- Analysis period}

All bleeding data starting at the day of implant insertion and ending at the day of implant removal (or last assessment if subject was lost to followup) were used for analysis. Bleeding data outside this analysis period (which was defined in agreement with the definition used for treatment duration in Section 7.3) were not taken into account.

\section{- Length of reference period}

The length of a reference period was defined as 90 days. Shorter reference periods were not included in the analysis. A 90-day reference period was used for this study because this duration was determined to be sufficient to allow several bleeding events to occur in a reference period. To be included in the analysis, a subject had to contribute at least one complete reference period of 90-day length.

- Interpolation rule for missing values If diary data with bleeding information were missing for $<2$ consecutive days, these missing values were converted to the same B-S response reported on the day immediately preceding the missing values (i.e., bleeding, spotting or bleeding-free was imputed). If this missing information occurred on the first one or two days of treatment, then the immediately following day was used for interpolation.

- Exclusion of reference periods

If diary data with bleeding information were missing for $3>3$ consecutive days the complete reference period of this subject was excluded from analysis. If these missing values were spread across 2 reference periods, the both reference periods were excluded.

\section{Data presentation}

The individual data of all excluded reference periods are presented.

For reporting, the amount of missing bleeding data and excluded reference periods, the number of interpolated missing values, the number of excluded reference periods, and the number of missing values within excluded reference periods (after interpolation) are tabulated in summary tables per reference period.

\section{Definition and handling of bleeding events}

The analysis of vaginal bleeding patterns was based on the following standard WHO definitions used for summarisation of diary data (Belsey et al, 1986, with a modification used for infrequent bleeding): 
1. a 'bleeding-spotting episode' was defined as any set of one or more consecutive bleeding or spotting days bounded at each end by at least one bleeding-free day;

2. a 'bleeding-free interval' was defined as any set of one or more consecutive bleeding and spottingfree days bounded at each end by at least one bleeding or spotting day;

3. 'amenorrhoea' was defined as no bleeding or spotting throughout the reference period;

4. 'infrequent bleeding' was defined as less than three $(0,1$ or 2$) \mathrm{B}-\mathrm{S}$ episodes starting within a reference period excluding amenorrhoea;

5. 'frequent bleeding' was defined as more than five B-S episodes starting within a reference period; and

6. 'prolonged bleeding' was defined by at least one B-S episode starting within a reference period and lasting more than 14 days.

The first two definitions (episodes and intervals) describe events which are summarised (with respect to number and length) within each single reference period. The following general conventions were used to handle these bleeding events in the analysis:

\section{- Events assignment}

All bleeding events (i.e. B-S episodes, bleedingfree intervals and prolonged bleeding) were assigned to the reference period in which they started and, therefore, counted exactly once (even if they ended in a later reference period).

\section{- Overlapping events}

The lengths of episodes and intervals were not truncated in any way if they overlapped two or more reference periods. Therefore, individual and mean event lengths of $>90$ days were possible. This convention was used regardless of whether or not subsequent reference periods were excluded from analysis.

\section{- Single-day bleeding-free intervals}

These intervals were analysed as they were recorded, that is, without treating them as part of the B-S episode surrounding them.

The following conventions were used in addition to handle incomplete events (episodes and intervals). These rules were applied in the order given below, with higher rules overriding following ones (thus, if an event was excluded from a statistic during one of these steps, it remained excluded).

\section{- First counted event}

The first counted event (episode or interval) which was in progress or starting at implant insertion was excluded from all statistics (number of events and length of events), but only if it was a B-S episode (thus if it was a bleeding-free interval, it was included with its cut-off length starting from Day 1); however, the number of days of this event was always counted (from Day 1).

\section{- Last counted event}

The last counted event (episode or interval) which was in progress at implant removal was included in the analysis with its cut-off (at implant removal) length if this event continued after the day of implant. The number of days of this event was always counted (ending at day of removal).

- Events bounded by missing values

Events which were right-truncated or left-truncated by $>3$ consecutive missing values were included in the analysis with full known length. These events were always counted in the reference period in which they started (an exception was only the 'first counted event' considered above). For example, right-truncated events continuing into an excluded reference period were counted in the reference period in which they started with actual length. Left-truncated events usually started in a reference period which was excluded from analysis. Therefore, only left-truncated events that started exactly on the first day of a reference period, were counted in that reference period with full known length.

\section{Summary statistics}

The following within-woman statistics were calculated for each subject for each reference period and are listed individually:

- number of bleeding days, spotting days, B-S days;

- number and mean length of B-S episodes;

- mean length and range of lengths of bleeding-free intervals; and

- incidence of amenorrhoea, infrequent bleeding, frequent bleeding, and prolonged bleeding.

If the number of events starting within a reference period was 0 , all length variables were defined as missing; also, if only one event occurred, the range (maximum minus minimum) of event lengths was set to missing. Based on these figures, summary statistics are presented per treatment group and reference period. The tables include mean, standard deviation (SD), 
minimum, maximum, median, lower and upper quartiles and $5^{\text {th }}$ and $95^{\text {th }}$ percentiles. Graphical presentations of these parameters per group and reference period are performed using modified box plots according to Turkey, which show, besides the usual quartiles (large box) also the $5^{\text {th }}$ and $95^{\text {th }}$ percentiles (small box) and the range. Similarly, the number and percentage of subjects with amenorhoea, infrequent bleeding, frequent bleeding, and prolonged bleeding are presented in frequency tables and appropriate bar charts.

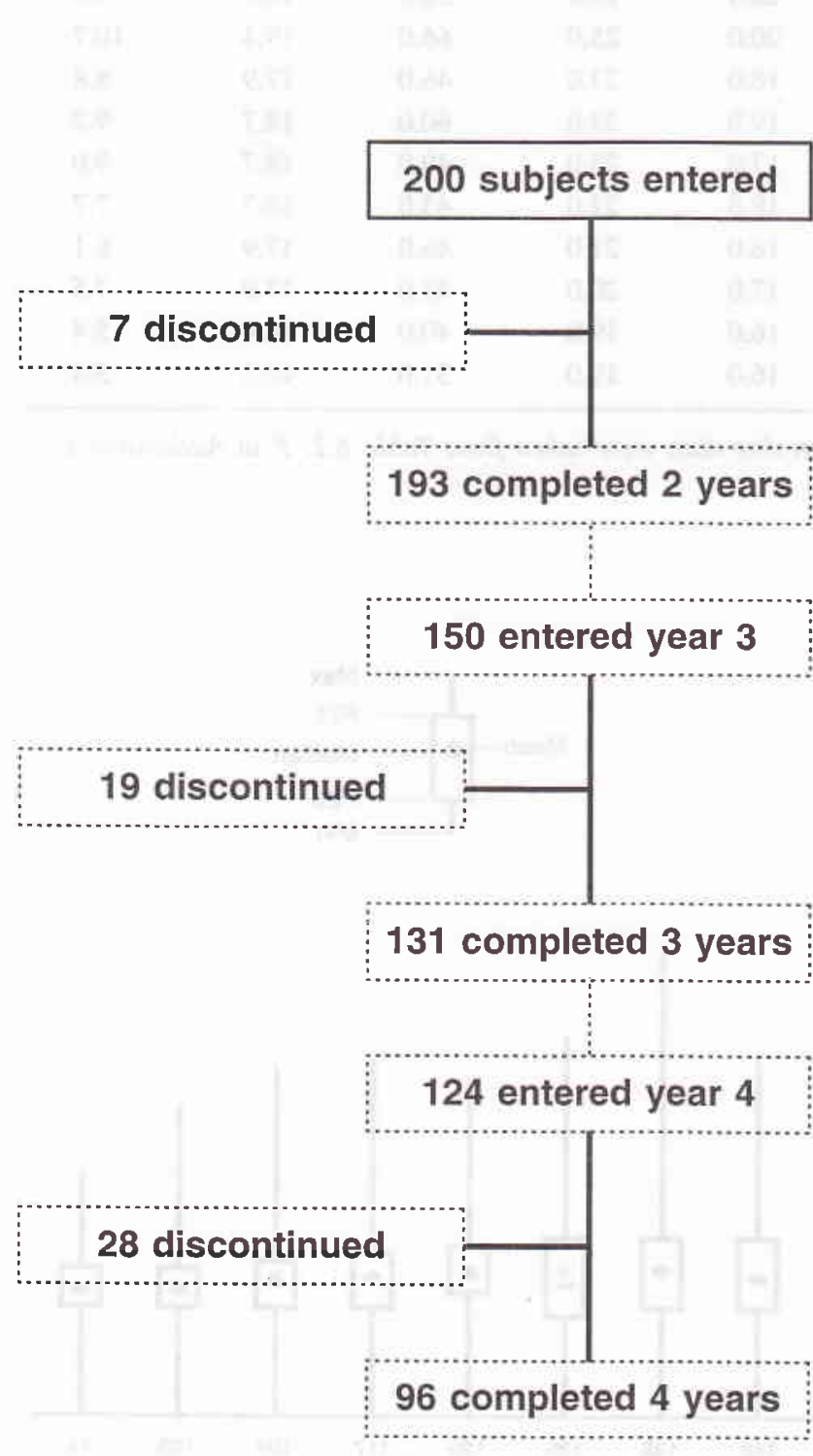

Figure 1. Disposition of subjects

\section{RESULTS}

\section{Profile of the subjects}

The profile of the subjects are described in Table 1. Age ranged from 20 to 35 years old with mean 28.3 years (SD 3.7)

The mean body weight was $49.8 \pm 8.1 \mathrm{~kg}$, while the mean height was $154.0 \pm 4.7 \mathrm{~cm}$, making the mean body mass index. All the subjects had already.

More than $39 \%$ of them being 3 or above. With regard to last contraceptive method use being $65.5 \%$ IUD and $30 \%$ of them had used no method at all.

Table 1. Profile of subjects $(\mathrm{N}=200)$

\begin{tabular}{lrr}
\hline Profile & Mean \pm SD & \multicolumn{1}{c}{$\%$} \\
\hline Age (years) & $28.3 \pm 3.7$ & \\
Height (cm) & $154.0 \pm 4.7$ & \\
Body Weight $(\mathrm{kg})$ & $49.8 \pm 8.1$ & \\
Body Mass Index $\left(\mathrm{kg} / \mathrm{cm}^{2}\right)$ & $21.0 \pm 3.0$ & \\
Parity : 1 - 2 & & 60.5 \\
$\quad 3-$ & 39.5 \\
Lost Contraception : & & \\
$\quad$ None & & 30.0 \\
$\quad$ Pill & & 1.5 \\
Implantables & & 1.0 \\
Injectables & & 1.0 \\
IUD & & 5.5 \\
Others & & \\
\hline
\end{tabular}

The mean number of bleeding-spotting days per $90-$ day reference period was highest during the first reference period (mean $26.7 \pm 17.6$ days). This number decreased quickly and ranged during the remainder of the study between 16.3 and 20.4 days with an average of 18.4 days (Figure 2). The mean number of bleeding-spotting episodes per reference period was highest during the first reference period (mean $3.3 \pm$ 2.1 ) and remained more or less constant during the study, ranging from 2.7 to 3.2 with an average of 2.9 episodes (Figure 3 ). 
Table 2. Number of bleeding-spotting days reference-period-analysis group

\begin{tabular}{|c|c|c|c|c|c|c|c|c|c|}
\hline \multirow[t]{2}{*}{ Group } & \multirow{2}{*}{$\begin{array}{c}\text { Reference } \\
\text { period }\end{array}$} & \multirow{2}{*}{$\begin{array}{c}\text { Subject } \\
\mathrm{N}\end{array}$} & \multicolumn{7}{|c|}{ Number of bleeding-spotting days } \\
\hline & & & Min & P25 & Median & P75 & Max & Mean & SD \\
\hline \multirow[t]{14}{*}{ Org 32222} & 1 & 193 & 1.0 & 14.0 & 22.0 & 37.0 & 83.0 & 26.7 & 17.6 \\
\hline & $\#$ & 195 & 0.0 & 10.0 & 19.0 & 34.0 & 82.0 & 23.9 & 18.3 \\
\hline & 2 & 197 & 0.0 & 10.0 & 18.0 & 28.0 & 83.0 & 20.4 & 16.4 \\
\hline & 3 & 195 & 0.0 & 9.0 & 17.0 & 24.0 & 71.0 & 18.3 & 13.2 \\
\hline & 4 & 193 & 0.0 & 9.0 & 17.0 & 24.0 & 71.0 & 17.8 & 13.0 \\
\hline & 5 & 191 & 0.0 & 11.0 & 19.0 & 25.0 & 59.0 & 19.1 & 12.0 \\
\hline & 6 & 192 & 0.0 & 14.0 & 21.0 & 24.5 & 53.0 & 19.5 & 11.0 \\
\hline & 7 & 192 & 0.0 & 15.0 & 20.0 & 24.0 & 50.0 & 18.3 & 9.5 \\
\hline & 8 & 184 & 0.0 & 14.0 & 20.0 & 25.0 & 66.0 & 19.4 & 10.7 \\
\hline & 9 & 146 & 0.0 & 14.0 & 18.0 & 23.0 & 46.0 & 17.9 & 8.8 \\
\hline & 10 & 138 & 0.0 & 14.0 & 19.0 & 23.0 & 60.0 & 18.7 & 9.2 \\
\hline & 11 & 135 & 0.0 & 13.0 & 17.0 & 23.0 & 49.0 & 18.7 & 9.0 \\
\hline & 12 & 129 & 0.0 & 16.0 & 18.0 & 22.0 & 43.0 & 18.7 & 7.7 \\
\hline & 13 & 117 & 0.0 & 14.0 & 18.0 & 21.0 & 46.0 & 17.9 & 8.1 \\
\hline & 14 & 104 & 0.0 & 14.0 & 17.0 & 20.0 & 45.0 & 17.9 & 7.5 \\
\hline & 15 & 103 & 0.0 & 14.0 & 16.0 & 19.0 & 40.0 & 16.4 & 5.4 \\
\hline & 16 & 74 & 0.0 & 14.0 & 16.0 & 19.0 & 31.0 & 16.3 & 5.4 \\
\hline
\end{tabular}

\# reference period of 90 days that starts 28 days after the insertion day data were taken from Table 6.2. F in Addendum $F$

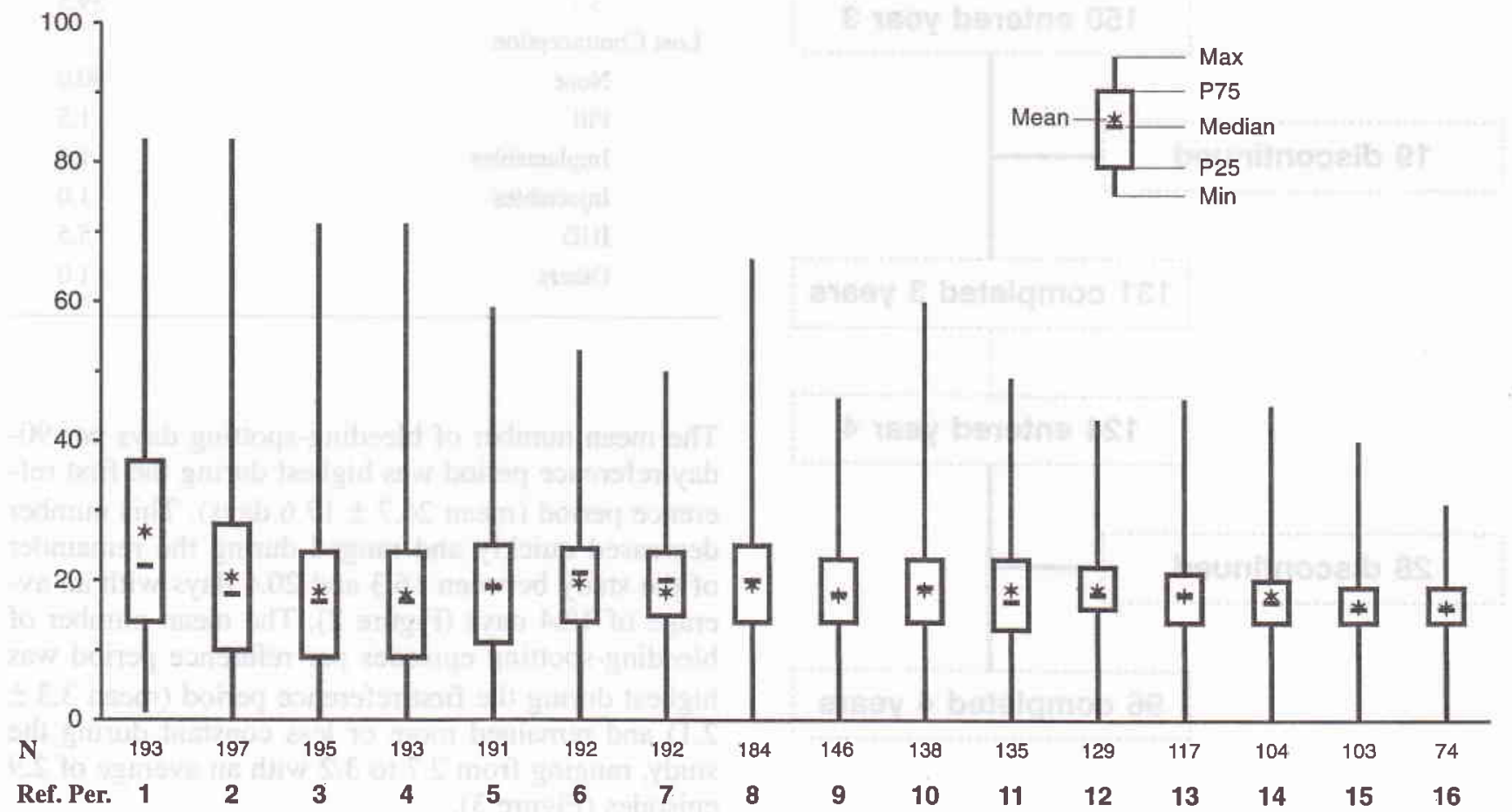

Figure 2. Number of bleeding-spotting days 
Table 3. Number of bleeding-spotting episodes reference-period-analysis group

\begin{tabular}{|c|c|c|c|c|c|c|c|c|c|}
\hline \multirow{2}{*}{ Group } & \multirow{2}{*}{$\begin{array}{c}\text { Reference } \\
\text { period }\end{array}$} & \multirow{2}{*}{$\begin{array}{c}\text { Subjects } \\
\mathrm{N}\end{array}$} & \multirow{2}{*}{\multicolumn{2}{|c|}{$\mathrm{P} 25$}} & \multicolumn{3}{|c|}{ Number of bleeding-spotting days } & \multirow{2}{*}{ Mean } & \multirow{2}{*}{$\mathrm{SD}$} \\
\hline & & & & & Median & P75 & Max & & \\
\hline \multirow[t]{17}{*}{ Org 32222} & 1 & 193 & 0.0 & 2.0 & 3.0 & 4.0 & 11.0 & 3.3 & 2.1 \\
\hline & $\#$ & 195 & 0.0 & 2.0 & 3.0 & 4.0 & 10.9 & 3.4 & 2.0 \\
\hline & 2 & 197 & 0.0 & 2.0 & 3.0 & 4.0 & 9.0 & 3.2 & 1.9 \\
\hline & 3 & 195 & 0.0 & 2.0 & 3.0 & 4.0 & 12.0 & 2.9 & 1.8 \\
\hline & 4 & 193 & 0.0 & 2.0 & 3.0 & 4.0 & 7.0 & 2.7 & 1.6 \\
\hline & 5 & 191 & 0.0 & 2.0 & 3.0 & 4.0 & 7.0 & 2.8 & 1.5 \\
\hline & 6 & 192 & 0.0 & 2.0 & 3.0 & 3.0 & 6.0 & 2.8 & 1.3 \\
\hline & 7 & 192 & 0.0 & 2.0 & 3.0 & 3.0 & 5.0 & 2.6 & 1.2 \\
\hline & 8 & 184 & 0.0 & 2.0 & 3.0 & 3.0 & 10.0 & 2.8 & 1.3 \\
\hline & 9 & 146 & 0.0 & 2.0 & 3.0 & 3.0 & 6.0 & 2.8 & 1.2 \\
\hline & 10 & 138 & 0.0 & 3.0 & 3.0 & 3.0 & 5.0 & 2.9 & 1.0 \\
\hline & 11 & 135 & 0.0 & 3.0 & 3.0 & 3.0 & 5.0 & 2.8 & 0.9 \\
\hline & 12 & 129 & 0.0 & 3.0 & 3.0 & 3.0 & 5.0 & 2.9 & 0.9 \\
\hline & 13 & 117 & 0.0 & 3.0 & 3.0 & 3.0 & 7.0 & 2.9 & 1.0 \\
\hline & 14 & 104 & 0.0 & 3.0 & 3.0 & 3.0 & 6.0 & 3.0 & 0.9 \\
\hline & 15 & 103 & 0.0 & 3.0 & 3.0 & 3.0 & 5.0 & 2.9 & 0.7 \\
\hline & 16 & 74 & 0.0 & 3.0 & 3.0 & 3.0 & 4.0 & 2.9 & 0.7 \\
\hline
\end{tabular}

\# reference period of 90 days that starts 28 days after the insertion day data were taken from Table 6.2. F in Addendum $F$

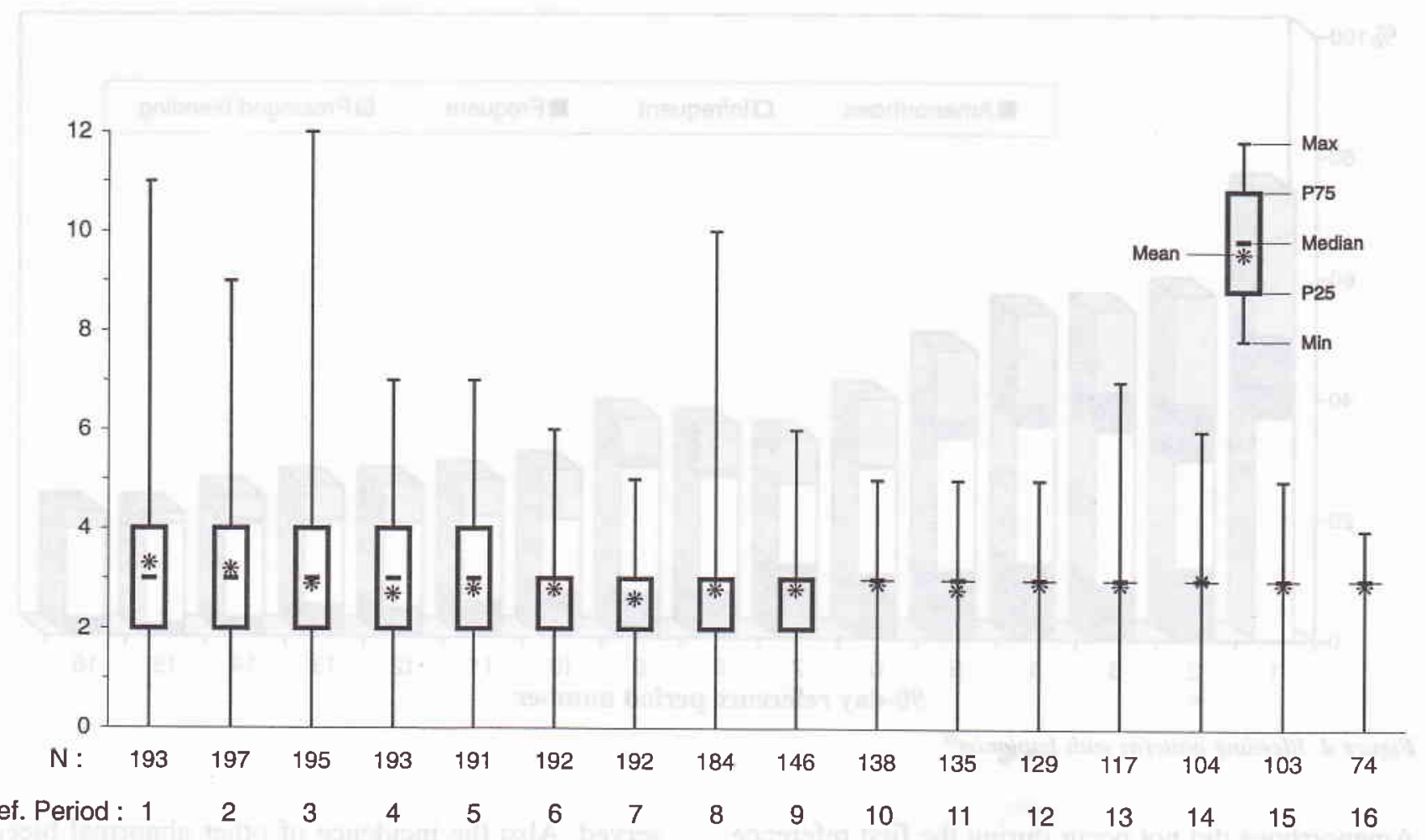

Figure 3. Number of bleeding-spotting episodes 
Table 4. Bleeding pattern indices reference-period-analysis group

\begin{tabular}{|c|c|c|c|c|c|c|c|c|c|}
\hline \multirow{2}{*}{$\begin{array}{c}\text { Reference } \\
\text { period }\end{array}$} & \multirow{2}{*}{$\mathrm{N}$} & \multicolumn{2}{|c|}{ Amenorrhoea } & \multicolumn{2}{|c|}{ Infrequent } & \multicolumn{2}{|c|}{ Frequient } & \multicolumn{2}{|c|}{ Prolonged bleeding } \\
\hline & & $\mathrm{n}$ & $\%$ & . & $\%$ & $\mathrm{n}$ & $\%$ & $\mathrm{n}$ & $\%$ \\
\hline 1 & 193 & 0 & & 71 & $(36.8)$ & 26 & $(13.5)$ & 46 & $(23.8)$ \\
\hline \# & 195 & 14 & (7.2) & 43 & $(22.1)$ & 27 & (13.8) & 47 & $(24.1)$ \\
\hline 2 & 197 & 23 & $(11.7)$ & 35 & $(17.8)$ & 19 & (9.6) & 35 & $(17.8)$ \\
\hline 3 & 195 & 17 & (8.7) & 50 & $(25.6)$ & 13 & $(6.7)$ & 26 & (13.3) \\
\hline 4 & 193 & 24 & (12.4) & 44 & $(22.8)$ & 7 & (3.6) & 29 & (15.0) \\
\hline 5 & 191 & 21 & $(11.0)$ & 42 & $(22.0)$ & 6 & $(3.1)$ & 22 & $(11.5)$ \\
\hline 6 & 192 & 20 & $(10.4)$ & 34 & $(17.7)$ & 1 & $(0.5)$ & 21 & (10.9) \\
\hline 7 & 192 & 23 & $(12.0)$ & 26 & (13.5) & 0 & & 14 & (7.3) \\
\hline 8 & 184 & 14 & $(7.6)$ & 35 & $(19.0)$ & 2 & $(1.1)$ & 13 & (7.1) \\
\hline 9 & 146 & 11 & $(7.5)$ & 30 & $(20.5)$ & 3 & $(2.1)$ & 9 & (6.2) \\
\hline 10 & 138 & 10 & $(7.2)$ & 17 & (12.3) & 0 & & 11 & (8.0) \\
\hline 11 & 135 & 8 & $(5.9)$ & 19 & (14.1) & 0 & & 8 & (5.9) \\
\hline 12 & 129 & 6 & $(4.7)$ & 18 & $(14.0)$ & 0 & & 8 & $(6.2)$ \\
\hline 13 & 117 & a: & $(5.1)$ & 16 & (13.7) & 1 & $(0.9)$ & 6 & (5.1) \\
\hline 14 & 104 & na $=$ & $(2.9)$ & 16 & $(15.4)$ & 1 & $(1.0)$ & 4 & (3.8) \\
\hline 15 & 103 & $x=$ & (1.9) & 17 & $(16.5)$ & 0 & & 2 & (1.9) \\
\hline 16 & 74 & 2 & $(2.7)$ & 11 & $(14.9)$ & 0 & & 2 & (2.7) \\
\hline
\end{tabular}

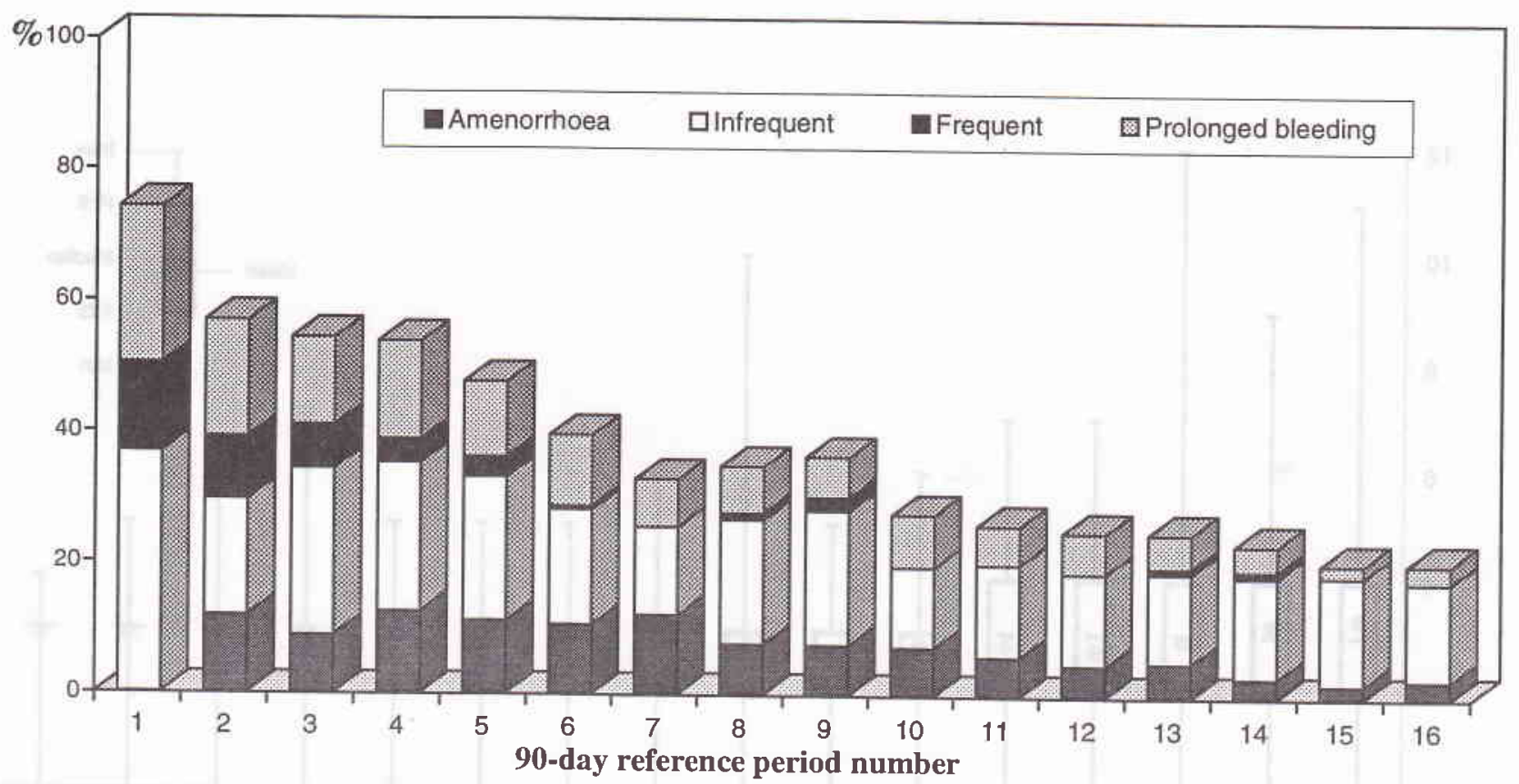

Figure 4. Bleeding patterns with Implanon ${ }^{\circledR}$

Amenorrhoea did not occur during the first reference period, but the incidence rate was 7.6-12.4\% during the remainder of the first two years. During years three (mean $6.4 \%$ ) and four (mean 3.3\%) a gradual reduction in the incidence of amenorrhoea was ob- served. Also the incidence of other abnormal bleeding patterns such as infrequent and frequent bleeding were higher during the first two years after which a gradual reduction was observed (Figure 4). Prolonged bleeding occurred in $10-20 \%$ of subjects in 
year one and decreased to $5-10 \%$ during years two to four. The bleeding pattern was well-tolerated, since only one subject discontinued early from the study because of amenorrhoea, while none of the subjects discontinued for irregular bleeding.

\section{DISCUSSION}

The bleeding pattern of women using Implanon ${ }^{\circledR}$ in comparison with Norplant ${ }^{\circledR}$ is currently being studied and data are not yet available. However, the bleeding pattern with Implanon ${ }^{\circledR}$ can indirectly be compared to results from other studies of women using Norplant ${ }^{\circledR 12,13}$ or women not using hormonal contraception ${ }^{14}$, since papers have recently been published in which bleeding in these groups has been analyzed with the '90-day reference period' methodology. The number of bleeding-spotting days with Implanon ${ }^{\circledR}$ was relatively high (median 22 days) during the first reference period, which was mainly because the implant was inserted during a bleeding episode. However, from the second reference period onwards, the Implanon ${ }^{\circledR}$ figure for bleeding-spotting days of 18 days was comparable to that observed in Norplant ${ }^{\circledR}$ users (18 days) and in non-users (19 days). Similarly, the median number of bleeding-spotting episodes was 3.0 during the first reference period, and remained stable during the remainder of the study, which is comparable to that reported in Norplant ${ }^{\circledR}$ users (3.0-3.2 episodes) and non-users (3.2 episodes). The proportion of women on Implanon ${ }^{\circledR}$ reporting amenorrhea, infrequent bleeding and prolonged bleeding decreased upon prolonged use of the method, and the occurrence of these bleeding disturbances with Implanon ${ }^{\circledR}$ was similar to that reported with Norplant ${ }^{\circledR 12,13}$ but always clearly higher than observed in non-users. ${ }^{14}$

One obvious reason for the higher incidence of bleeding irregularities with progestogen-only contraceptives such as Implanon ${ }^{\circledR}$ and Norplant ${ }^{\circledR}$ in comparison with non-users is related to the central suppresion of gonadotropin secretion and the inhibition of ovulation with persistent follicular activity and fluctuating estradiol levels. 15 Another reason for bleeding irregularities, especially of prolonged scanty periods, is the progestogen induced induction of endometrial atrophy accompanied by an increased microvascular density. 16

\section{Acknowledgement}

This study was conducted as part of Implanon ${ }^{\circledR}$ Research and Development Program sponsored and coordinated by NV Organon, Oss, the Netherlands.

Thanks are due to Dr. Stevenson from N.V. Organon Holland for Good Clinical Practice Monitoring, to Drs. Wardoyo Gadroen, Bandar Damanik and Susilo from Organon Indonesia for study monitoring, to Dra. Rosminah from Klinik Raden Saleh for patients coordination, to Drs. AGM Theeuwes and RMV Stoleman from SOG NV Organon and to Dr. Joedo Prihartono and Sujadi from Department of Community Medicine-University of Indonesia, Jakarta for data analysis and to Ms. Sofia Yoebhaar for typing the manuscript.

\section{REFERENCES}

1. Fatthalla MF. A synthesis of various experiences and problems encountered with available methods of fertility regulation in developing countries. In: Research on the Regulation of Human Fertility - Needs for Developing Countries and Priorities for the Future (E. Diczfalusy and A. Diczfalusy, Editor). Scriptor, Copenhagen 1983; p. 76-92

2. Affandi B, Santoso SSI, Djajadilaga et al. Five year experience with Norplant ${ }^{\circledR}$. Contraception 1987; 36: 417-28

3. WHO. A multicentred Phase III comparative clinical trial of DMPA given 3-monthly at dose of $100 \mathrm{mg}$ and $150 \mathrm{mg}$ : II. The comparison of bleeding patterns. Contraception 1987 ; 35: $591-610$

4. WHO. A multicentered Phase III comparative study of two hormonal contraceptive preparations given once-a-month by intramuscular injection II. The comparison of bleeding patterns. Contraception 1989; 40: 531-51

5. Meng, Gu S. Menstrual bleeding patterns in Chinese women using the Norplant ${ }^{\circledR}$ subdermal implant. Human Reproduction 1996; 11 S2: 14-9

6. WHO. Clinical evaluation of therapeutic effectiveness of ethynil oestradiol and oestrone sulphate on prolonged bleeding in women using dept medroxyprogesterone acetate for contraception. Human Reproduction 1996; 8, 52: 1-13

7. Kovacs G. Progestogen-only pills and bleeding disturbances. Human Reproduction 1996; 11, 52: 20-3

8. Archer DF, Philput CA, Weber ME. Management of irregular uterine bleeding and spotting associated with Norplant ${ }^{\circledR}$. Human Reproduction 1996; 11, S2: 24-30

9. Fraser IS. Vaginal bleeding patterns in women using. Oncea-month injectable contraceptives. Contraception 1994; 49 : $399-420$ 
10. Belsey EM, Machin D, d'Arcangues C. The analysis of vaginal bleeding patterns induced by fertility regulating methods. Contraception 1986; 34: 253-60

11. Belsey EM, Farley TMM. The analysis of menstrual bleeding patterns: a review. Contraception 1988; 38: 129-56

12. Sivin I. Contraception with Norplant ${ }^{\circledR}$ implants. Hum Reprod 1994; 9: 1818-26

13. Biswas A, Leong WP, Ratnam SS, Viegas OAC. Menstrual bleeding patterns in Norplant ${ }^{\oplus}-2$ implant users. Contraception 1996; 54: 91-5
14. Belsey EM, Pinol APY, and Task Force on Long-Acting Systemic Agents for Fertility Regulation. Menstrual bleeding patterns in untreated women. Contraception 1997; 55: 57-65

15. Odlind V. New methods of fertility regulation in women. Clin Reprod Fertil 1987; 3: 221-35

16. Rogers PAW, Au CL, Affandi B. Endometrial microvascular density during the normal menstrual cycle and following exposure to long-term levonorgestrel. Hum Reprod 1993; 8: 1396-404. 